\title{
EXAMINING THE EVENT SERVICE QUALITY FOR TRAVELERS WITH MOBILITY IMPAIRMENTS BY KOREAN CAREGIVERS' PERSPECTIVE
}

\author{
SANGGUK KANG,* HEEYOUN KIM,† SHU COLE, $₫$ AND JENNIFER A. PIATT $\$$ \\ *Department of Tourism Management, College of Social Sciences, \\ Gangneung-Wonju National University, Gangwon-do, Korea \\ $\dagger$ University of Florida, Gainesville, FL, USA \\ $\$$ Department of Recreation, Park, \& Tourism Studies, Indiana University School of Public Health, \\ Bloomington, IN, USA
}

\begin{abstract}
Travelers with mobility impairments (TwMI) often have difficulty traveling alone due to various constraints and barriers. Caregivers of TwMI might play an important role in mitigating these constraints and barriers for TwMI. Knowing the event service quality for TwMI from the point of view of caregivers is essential for better quality of travel for both caregivers and TwMI. So far, although event service quality is important for people with disabilities, most of the studies have been conducted with people without disabilities. As caregivers' opinion is critical for deciding event participation, this study focused on perspective of caregivers regarding event service quality for TwMI. This study utilized structure equation modeling (SEM) analysis to empirically examine the relationship among event service quality for TwMI in terms of perspective of caregivers who accompanied TwMI to the event, caregivers' event satisfaction with TwMI, and caregivers' behavior intentions. From two event service qualities for TwMI, only service environment quality for TwMI demonstrated statistical significance on caregivers' event satisfaction with TwMI while service provider quality for TwMI had no statistical significance on both caregivers' event satisfaction with TwMI and caregivers' behavior intention. Caregivers' event satisfaction with TwMI demonstrated statistical significance on caregivers' behavior intention. Overall, this study may provide practical information to event organizers and other hospitality industries related to service quality for TwMI from various points of view.
\end{abstract}

Key words: Caregivers; Travelers with mobility impairment (TwMI); Event service quality; Caregivers' event satisfaction; Caregivers' behavior intention

Address correspondence to Sangguk Kang, Ph.D., Department of Tourism Management, College of Social Sciences, Gangneung-Wonju National University, Building C-1 328, 25457, Jukheon-gil 7, Gangneung-si, Gangwon-do, Korea. E-mail: kriver39@gwnu.ac.kr 


\section{Introduction}

Although travel is usually a pleasant experience for most of the travelers without disabilities, for travelers with disabilities travel might be challenge, which needs to be overcome from an uncaring society and an apathetic travel industry (Sato, Yoshida, Wakayoshi, \& Shonk, 2016; Shaw $\&$ Coles, 2004). Furthermore, travelers with disabilities encounter various constraints and barriers (e.g., lack of accessible facilities, inconvenient access from home to the tourist destination, lack of accurate travel information related access, unreliable information from travel agents, negative attitude) when they travel due to limitations, either physically or mentally (e.g., Bi, Card, \& Cole, 2007; Bombom \& Abdullahi, 2016; Brown, Kaplan, \& Quaderer, 1999; Burnett \& Baker, 2001; Darcy \& Daruwalla, 1999; Israel, 2002; Ray \& Ryder, 2003; Takeda \& Card, 2002; Turco, Stumbo, \& Garncarz, 1998). In addition, travelers with disabilities might have no alternative choices to travel to certain tourist destinations when barriers and constraints (e.g., accessibility) are beyond their control (Yau, McKercher, \& Packer, 2004). In this context, although travelers with disabilities possess the same desires as others without disabilities, these constraints and barriers can lead to frustration and a state of helplessness, and finally reach loss of intention to travel (B. K. Lee, Agarwal, \& Kim, 2012; Yau et al., 2004).

However, travelers with disabilities might have more confidence and enjoyment when they travel with caregivers since caregivers play an important role in reducing constraints and lowering barriers (Mckercher, Packer, Yau, \& Lam, 2003; Yau et al., 2004). As a caregiver is a person who is responsible for helping people with disabilities such as a family member, friend, or relative, the caregiver's role is especially important when travelers with disabilities encounter barriers during travel by alleviating the stress caused by inconvenience and uncomfortable circumstance (Bedini, 2002; Wiles, 2003). Furthermore, a caregiver's positive perspective toward travel might play a critical role in deciding to visit travel places with people with disabilities. Most importantly, traveling together with both caregivers (i.e., family, friends) and care recipients can enhance their relationship as an important part of life (Gladwell \& Bedini, 2004; Shi, Cole, \& Chancellor, 2012).

According to the Korea Employment Agency for the Disabled report (2015), the number of people with a disability was less than 1 million in 2000 , while a recent census report showed that the number of South Koreans with disabilities was almost 2.4 million at the end of 2014, and the number will increase as a result of longer life expectancy and medical improvements. In addition, almost 1.3 million people are in the group of mobility impairments, which is more than half of the total 2.4 million people with disabilities in South Korea. Although some people with disability go out for work, to go to the hospital, to do short distance exercise, and meet friends, less than $10 \%$ of the people with disability spent time for travel purposes (Korea Employment Agency for the Disabled, 2015). Although South Korea enacted the Disability Discrimination Act in 2008 and made an effort to guarantee better travel as people without disability do, many people with disabilities still struggle and are reluctant to travel by themselves because of inaccessible environment and unfavorable attitudes toward people with disability. In addition, even though public tourist destinations (e.g., museum, event area) are well equipped with accessible facilities for travelers with mobility impairment (TwMI), accessible public transportation is still highly limited and some places have an inaccessible physical environment (i.e., stairs, narrow sidewalk). Most importantly, because more than $77 \%$ of people with disability need help from caregivers even in daily life, less than $10 \%$ for people with disabilities travel is explainable by Korea's current situation (Korea Employment Agency for the Disabled, 2015). In addition, in terms of Korean culture, Korean TwMI prefer to travel with their care providers due to close relationships from daily life and a sense of solidarity with each other (Jeong, An, Park, \& Park, 2016; Lyu, 2017). Therefore, it is important to know why caregivers' perspective is important when they travel with TwMI. When considering travelers with disabilities typically travel with their caregivers (e.g., family, friends), the importance of a market with both caregivers and people with disabilities is undeniable in the competitive event industry (Kahn, 2000; B. K. Lee et al., 2012). Therefore, travel industries need to pay more attention to caregivers' favorable perception of the travel experience (Gladwell \& Bedini, 2004; Yates, Tennstedt, \& Chang, 1999). 
Although ample studies have found significant relationships among event service quality, event satisfaction, and behavior intention in the marketing, sport, tourism, and event management literature, research has mostly focused on the perspective of people without disabilities (e.g., Getz, O'Neill, \& Carlsene, 2001; Hall, Oriade, \& Robinson, 2016; Theodorakis, Kaplanidou, \& Karabaxoglou, 2015). In addition, although the market of travelers with disabilities is becoming more important in the tourism industry as the largest minority group, and with remarkable growth of population of people with disabilities, research for event service quality for people with disabilities has yet to be examined (Huh \& Singh, 2007). Because many travelers with disabilities travel with care providers, unraveling the service quality through the perspective of caregivers is important because care providers might play an important role in influencing the travel decision-making processes and affirmative service perception might positively relate with increased travel with people with disabilities (B. K. Lee et al., 2012). Although all kinds of people with disabilities (e.g., vision, hearing) are important in the tourism market, this study only focused on caregivers with TwMI, who are one of the largest groups of people with disabilities in the event area (Brault, 2012; Lyu, Oh, \& Lee, 2013).

\section{Literature Review}

\section{Barriers to TwMI and Role of Caregivers}

Many people with disabilities encounter physical, social, economic, and attitudinal barriers to participate in many aspects of society that exclude them from accessing entirely and effectively as equal members of society (Bi et al., 2007). TwMI especially struggle when they plan travel because of barriers such as physically inaccessible facilities and insufficient travel information (Avis, Card, \& Cole, 2005; Doshi, Furlan, Lopes, DeLisa, \& Battistella, 2014). For instance, Turco et al. (1998) conducted focus group interviews with Illinois individuals with disabilities and found that travel sites and facilities need comfortable accessibility, reliable travel informants, flexible transportation, and policy compliance. Darcy and Daruwalla
(1999) categorized major constraints that people with physical disability encounter when they travel as the lack of (1) access to physical infrastructure needs, (2) accessible accommodation, (3) access at the destination and to the attractions, and (4) lack of accurate information. Especially, TwMI are highly sensitive to accessibilities when they travel because accessibility attributes "cannot be compensated for by a surplus in any other attribute" (Israel, 2002, p. 102). Ray and Ryder (2003) conducted informal focus group interviews and found that TwMI would not travel to inaccessible travel destinations and distrusted travel agents because actual destinations are sometimes different than explained on brochures and websites.

The negative attitudes of others, such as employees at the travel destination, are also one of the sensitive issues at hand when people with disabilities consider travel (Bi et al., 2007; Takeda \& Card, 2002). Daniels, Rodgers, and Wiggins (2005) studied travel constraints and negotiation strategy with people with physical disabilities. Daniels and colleagues coded and interpreted the travel comments by TwMI and their travel companions from travel websites, and categorized constraints based on intrapersonal, interpersonal, and structural conditions. Among these three constraints, structural themes showed the highest constraints (i.e., transportation, facility, environment). With these unfavorable conditions, TwMI are less likely to travel to unfamiliar places due to a number of barriers such as uncomfortable facilities and discriminatory attitudes toward disabilities, and culmination of these constraints and barriers can be a loss of willingness to travel (Avis et al., 2005; Bi et al., 2007; Gladwell \& Bedini, 2004; B. K. Lee et al., 2012). As TwMI encounter various barriers (i.e., inaccessible facility, inaccurate information pertaining to accessibility, negative attitude) when they travel, caregivers can play a significant role in accompanying people with disabilities as a reliable travel partner, mitigating barriers such as nonaccessible facilities, and reducing emotional stress (Gladwell \& Bedini, 2004; McKercher et al., 2003). Therefore, travelers with disabilities might have less concern traveling and can increase their willingness to travel with caregivers who enable travelers with disabilities to maximize positive travel experiences. 
Event Service Quality, Event Satisfaction, and Behavior Intention

As an important pull factor and important motivator in tourism (Gnoth, 1997), event quality has played an important role in attracting tourists and contributing to other relevant tourism industry development because event visitors' expenditures positively impact local restaurants, other tourist destinations, and hotels (Getz \& Page, 2016). Although unique and enjoyable event programs induce tourists, it is the general belief that highly well-managed event service quality is indispensable for successful events (e.g., Brady \& Cronin, 2001; Brady \& Robertson, 2001; Hansemark \& Albinson, 2004; Kelly \& Turley, 2001; Murray \& Schlacter, 1990; Parasuraman, Zeithaml, \& Berry, 1985; Stum \& Thiry, 1991; Zeithaml, Berry, \& Parasuraman, 1996).

For instance, Baker and Crompton (2000) conducted research on the relationships among event service quality (i.e., generic features, specific entertainment features, information sources, comfort amenities) and satisfaction based on quality of the experience and behavior intentions with loyalty to the event and willingness to spend more money. The result also showed that event service quality positively impacted both satisfaction and behavior intentions. Cronin, Brady, and Hult (2000) studied the relationship among service quality, service value, satisfaction, and behavioral intention with six different industries (i.e., spectator sports, participant sports, entertainment, fast food, healthcare, long-distance carriers) and the results showed that service quality is positively connected to the satisfaction and behavior intentions. Getz et al. (2001) reported that highly trained and customer-friendly staff members and volunteers are one of the important factors for forming positive visitor experiences. Mason and Nassivera (2013) studied the relationships among perceived service quality, satisfaction, awareness, and behavior intention by using food and wine events in Italy. From the results, service quality positively influenced both satisfaction and behavior intention, and satisfaction also showed positive influences on behavior intention.

Similar to event service quality, Y. K. Lee, Lee, Lee, and Babin (2008) developed the term festivalscapes, which consists of seven dimensions of festival quality (program content, staff service, facilities, food, souvenirs, convenience, and information availability) based on notion of "servicecape" (Bitner, 1992). From the results, among the seven dimensions, only three dimensions (program contents, food, and facilities) showed enhancing loyalty indirectly over satisfaction. After that, similarly, J. S. Lee, Lee, and Yoon (2009) categorized two event participant groups (first-time participants and repeat participants) to find the relationship among festival quality (i.e., informational service, program, souvenir, food, convenient facility), event value, and event loyalty. They found first-time visitors' event value is positively connected with the program's convenient facilities, food, and souvenirs. On the other hand, repeat visitors' event value is only positively related to the program and convenient facilities and showed a higher relationship than first-time visitors. Although both first-time and repeat visitors' event value positively connected with event loyalty, repeat visitors showed stronger loyalty than first-time event visitors. This study presented that event strategy should be different based on times of event participation and at least both the event program and convenient facilities are critical for continuous repeated event participation. Song, Ahn, and Lee (2015) empirically examined how Expo experience and Expo quality influence visitor satisfaction. Expo experience consisted of four factors that were comprised of educational, escape, esthetic, and entertainment experiences, while Expo quality was used with one dimension (i.e., convenience facilities, friendly staff, easy-to-use information). They found that two factors (esthetic and entertainment) in Expo experiences and Expo quality positively influenced visitor satisfaction. Previous research suggests that service quality has a significant effect on both customer satisfaction and behavior intentions such as word-of-mouth and intention to revisit. However, although ample studies have identified the importance of service quality, the perspective of caregivers who accompany travelers with disabilities have not been examined yet. Consequently, the purpose of the current research was to examine how the event service quality for TwMI in terms of the perspective of caregivers who accompanied TwMI impact caregivers' event satisfaction with TwMI and caregivers' behavior intention. 
In detail, this study states the following hypotheses:

H1: Event service quality for TwMI will positively affect caregivers' event satisfaction with TwMI.

H2: Event service quality for TwMI will positively affect caregivers' behavior intention.

H3: Caregivers' event satisfaction with TwMI will positively affect caregivers' behavioral intention.

\section{Method}

\section{Participants and Procedure}

A total of 230 surveys were collected from caregivers who accompanied TwMI who visited the 2012 YEOSU Expo in South Korea. Of the surveys collected, 214 were usable. This study used convenience sampling procedure and surveys were collected during the afternoon time near the exit gates of the venue when visitors were on their way back home so visitors would have had enough time to experience the event site. To obtain a representative sample of TwMI, caregivers who accompanied wheelchair users were intercepted. Once caregivers had agreed, the participants were given an explanation on the purpose of the survey and were asked to complete the questionnaire on event service quality for TwMI, caregivers' event satisfaction with TwMI, and caregivers' behavior intention. Average time for survey completion took 10-15 min. A cross sectional study was conducted and participants filled out survey on a voluntary basis.

\section{Measurement}

Although the majority of research has conducted event service quality (e.g., Baker \& Crompton, 2000; Cole \& Illum, 2006; Cole \& Scott, 2004; Crompton \& Love, 1995; J. S. Lee, Lee, \& Choi, 2011; Getz et al., 2001), most studies have operationalized for abled people. Because this research designed event service quality for TwMI from the perspective of caregivers, this is the first study to examine the relationship among event service quality for TwMI, caregivers' event satisfaction with TwMI, and caregivers' behavior intention.
Therefore, the measurement items were developed through interviews of caregivers and evaluation from professionals.

First, researchers initially interviewed 10 caregivers who accompanied TwMI at the event area with open-ended questionnaires. With this procedure, a preliminary list of measurement items for event service quality for TwMI from the perspective of caregivers was initially developed. Although some of the event service quality items are similar with those for abled people (e.g., restroom, helpfulness of staff), caregivers mostly focused on event service quality for TwMI largely as convenient access to the facilities (e.g., restroom, entrance, event space, restaurant), availability of assistive devices (e.g., wheelchair), and help from event staff (e.g., possess proper information for TwMI, willingness to help). Second, after the interviews, items were screened and clarified by five people including researchers, travel agents who specialize in accessible travel, event managers, social welfare workers, and caregivers to see if the items of event service quality for TwMI were adequately associated with the event context. Third, a pretest was conducted on 18 caregivers who accompanied TwMI to further refine the list of items and finalize the survey instrument. Because the pretest were conducted at the same event where initial interviews conducted, the results of the pretest were useful to verify ambiguous event service quality items for TwMI and develop additional event service quality elements for TwMI. With this procedure, the measure for event service quality for TwMI was developed in accordance with the event context.

A total of 11 event service quality items for TwMI (e.g., convenient to move in the event area for TwMI, convenient entrance for TwMI, convenient places for assistive device rental for TwMI, staff possess proper information for TwMI) were finally used from the results of the above procedures, which represents various aspects of event service quality for TwMI in terms of caregivers' point of view in the event context. Regarding caregivers' event satisfaction with TwMI measurement, three questionnaire items were adopted from tourism studies and questionnaire items were slightly modified (J. S. Lee et al., 2011; C. K. Lee, Yoon, \& Lee, 2007). Caregivers' event satisfaction with TwMI included three observed variables: (1) Overall, how satisfied were you with your visit to the 
event with TwMI? (2) How would you rate your satisfaction with TwMI, considering what you expected? (3) How would you rate your satisfaction compared with your time and effort in visiting the event with TwMI? Caregivers' behavioral intention scales were adopted and modified from J. S. Lee et al. (2011), and Cole and Scott (2004). Two variables were recommendations (e.g., I would like to recommend to other caregivers who accompany people with disabilities) and one variable was intention to visit other similar events (i.e., I would like to visit similar events with TwMI).

Thus, this study posits hypotheses as follows:

H1a: Service environment quality for TwMI positively affect caregivers' event satisfaction with TwMI.

H1b: Service environment quality for TwMI will positively affect caregivers' behavior intention.

H2a: Service provider quality for TwMI positively affects caregivers' event satisfaction with TwMI.

H2b: Service provider quality for TwMI will positively affect caregivers' behavior intention.

H3: Caregivers' event satisfaction with TwMI will positively affect caregivers' behavioral intention.

All responses were measured on a 7-point Likert scale, with $1=$ strongly disagree to $7=$ strongly agree. Regarding data analysis, descriptive analyses, exploratory factor analysis (EFA), and confirmatory factor analysis (CFA) were executed with SPSS 23, while structural equation modeling (SEM) was employed with AMOS 23 programs.

\section{Result}

\section{Demographic Information}

A summary of demographic characteristics for both caregivers and TwMI is provided in Table 1. Out of 214 participants, a little over half of the caregiver respondents were male $(55.6 \%, N=119)$ and $44.4 \%$ were female $(N=95)$ while female TwMI $(54.7 \%$, $N=117)$ were a little bit more than male TwMI $(45.3 \%, N=97)$. The most prevalent respondent age category for caregivers was $21-40$ years old $(48.2 \%)$, followed by 41-60 (37.3\%), and over $61(14.5 \%)$. On the other hand, the most predominant TwMI age category was over 61 years old (63.1\%), followed by under $20(15.9 \%)$, 41-60 (11.6\%), and 21-40 (9.3\%). Regarding the relationship between caregivers and TwMI, the majority of the caregiver respondents were family members $(93 \%)$ and this result reflects that TwMI more frequently travel with their family members than other caregiver groups such as friends or public organizations. With decision making for travel, mostly caregivers and public organization (86\%) decided to visit the event with TwMI.

Descriptive Analysis of Event Service Quality for TwMI, Caregivers' Event Satisfaction With TwMI, and Caregivers' Behavior Intention

Analyses of outliers, normality, missing data, and multicollinearity were performed to reduce

Table 1

Demographic Information of Caregivers and Travelers With Mobility Impairments (TwMI) $(N=214)$

\begin{tabular}{lccr}
\hline Characteristics of Caregivers & $N(\%)$ & Characteristics of TwMI & $N(\%)$ \\
\hline Gender & & Gender & \\
$\quad$ Male & $119(55.6)$ & Male & $97(45.3)$ \\
Female & $95(44.4)$ & Female \\
Age & 0 & Under 20 & $117(54.7)$ \\
Under 20 & $103(48.2)$ & $21-40$ & $34(15.9)$ \\
$21-40$ & $80(37.3)$ & $41-60$ & $20(9.3)$ \\
$41-60$ & $31(14.5)$ & Over 61 & $25(11.6)$ \\
Over 61 & Decision making for event participation by & $135(63.1)$ \\
Relationship between caregivers and TwMI & $199(93)$ & Caregivers & $174(81.3)$ \\
Family members & $3(1.4)$ & TwMI & $30(14)$ \\
Friend & $12(5.6)$ & Public organization & $10(4.7)$ \\
Public organization & & &
\end{tabular}




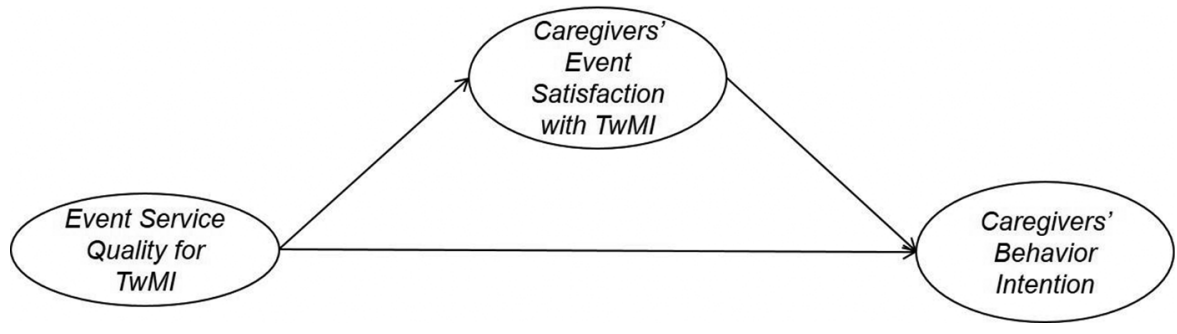

Figure 1. Conceptual model.

systematic errors and refine the data. No specific outliers were detected when examined with standard deviation and all 11 event service quality for TwMI items were shown as normally distributed when examined with skewedness and kurtosis. Descriptive statistics were conducted to identify mean scores of the 11 event service quality for TwMI items, three caregivers' event satisfactions with TwMI items, and three caregivers' behavior intention items (see Fig. 1).

Table 2 shows the descriptive analysis and all event service quality for TwMI items mean score presented above the mid-scale point of 4 . In detail, the highest event service quality for TwMI of the items was "convenient use of restroom for TwMI"
$(M=6.04)$ and the lowest item was "convenient use of restaurant with TwMI" $(M=4.31)$. Caregivers' event satisfaction with TwMI indicated that all items were above a score of 5 and all behavior intention items showed a score above 6. Overall, mean values represented that event service quality for TwMI, caregivers' event satisfaction with TwMI, and caregivers' behavior intention is fairly favorable to the event. Cronbach's alphas for the event service quality for TwMI were 0.890 , caregivers event satisfaction with TwMI were 0.893 , and caregivers' behavior intention were 0.914. All of these Cronbach's alphas were acceptable and reliable because they exceeded the suggested adequate value of 0.70 (Nunnally \& Bernstein, 1994).

Table 2

Results of Descriptive Analysis of Event Service Quality for TwMI, Caregivers' Event Satisfaction With TwMI, and Caregivers' Behavior Intention

\begin{tabular}{llc}
\hline & Mean $(S D)$ & Cronbach's Alpha \\
\hline Event service quality for TwMI & & 0.890 \\
Convenient to move in the event area for TwMI & $5.44(0.858)$ & $5.75(0.835)$ \\
Convenient places for assistive device rental for TwMI & $6.04(0.913)$ \\
Convenient use of restroom for TwMI & $4.94(0.928)$ \\
Well-equipped assistive device (e.g., wheelchair) for TwMI & $5.32(0.966)$ \\
Convenient view of event programs for TwMI & $5.16(1.004)$ \\
Convenient entrance for TwMI & $4.31(1.043)$ \\
Convenient use of restaurant with TwMI & $5.16(0.957)$ \\
Staff are located proper location for TwMI & $5.33(0.875)$ \\
Staff are kind to TwMI & $4.84(1.038)$ \\
Staff possesses proper information for TwMI & $5.22(0.863)$ \\
Staff are willing to help for TwMI & \\
Caregivers' event satisfaction with TwMI & $5.64(0.730)$ \\
Overall satisfied event with TwMI & $5.66(0.760)$ \\
Satisfied event with TwMI when compared with my expectation & $5.80(0.810)$ \\
Satisfied event with TwMI when considering my invested time and effort & $6.00(0.825)$ \\
Caregivers' behavior intention & $6.15(0.837)$ \\
I would like to visit other similar events with TwMI & $6.41(0.781)$ \\
I would like to say positive things about the event to other caregivers or TwMI & 0.893 \\
I would like to recommend the event to other caregivers or TwMI & 0.914 \\
\hline
\end{tabular}


Exploratory Factor Analysis (EFA) With Event Service Quality for TwMI

Although there is numerous research conducted on event service quality items for abled people, there is no research specifically for TwMI. Because this is the first time to conduct event service quality for TwMI in terms of caregivers' perspective and new items were developed from initial interviews and a pretest, an EFA test was conducted. First, EFA with varimax rotation was examined to identify underlying dimensions of the event service quality for TwMI scale. Each factor item was used with latent root criterion (eigenvalue) of 1.0 and over 0.40 factor loading. The Kaiser-Meyer-Olkin $(\mathrm{KMO}=0.863)$ measure of sampling adequacy and Bartlett's test of sphericity showed the appropriateness of factor analysis with the level of $p<0.001$.

As a result of the EFA test, two factors were derived from the 11 event service quality for TwMI items by perspective of caregivers, explaining $58.8 \%$ of variance. Based on the loadings and elements of factor information, two factors were derived and labeled as "service environment quality for TwMI" (eigenvalue $=5.33$, explained variance $=48.46 \%$ ) and "service provider quality for TwMI" (eigenvalue $=1.13$, explained variance $=10.34 \%$ ) based on the information of loadings and contents of the factors. Service environment quality consisted of seven observed variables [e.g., "Do you think the event area is convenient to move for TwMI?" "Do you think the event provides convenient use of restroom for TwMI?" "Do you think the event area is well-equipped assistive device (e.g., wheelchair) for TwMI?"]. Cronbach's alpha with seven items were fairly high with 0.866 . Service provider quality was composed of four observed variables (e.g., "Do you think the event staffs possess proper information for TwMI?" "Do you think the event staffs are willing to help for TwMI?"). Cronbach's alpha was 0.828 with four items (see Table 3 ).

\section{Confirmatory Factor Analysis (CFA) for Overall Measurement Model and Structural Equation Model (SEM)}

CFA was conducted to assess the measurement properties of the selected constructs and factors (Arbuckle, 2006). The final CFA measurement model included 17 items: two exogenous latent constructs (service environment quality for TwMI with 7 items, service provider quality for TwMI with 4 items), two endogenous latent constructs (caregivers' event satisfaction with TwMI with 3 items, caregivers' behavior intention with 3 items), which was tested to see if the hypothesized model fit the collected sample data. As shown in Table 4, correlations among research variables were acceptable, ranging from 0.49 to 0.81 , which indicates the discriminant validity of the measures (Kline, 2005). Taken together, the results provide strong evidence for the convergent and reasonable level of discriminant validity

Table 3

Result of Factor Analysis of Event Service Quality for TwMI $(N=214)$

\begin{tabular}{|c|c|c|c|}
\hline Factors & Factor Loading & Eigenvalue & Explained Variance \\
\hline Service environment quality for TwMI & & 5.331 & 48.462 \\
\hline Convenient to move in the event area for TwMI & 0.798 & & \\
\hline Well-equipped assistive device (e.g., wheelchair) for TwMI & 0.754 & & \\
\hline Convenient use of restroom for TwMI & 0.637 & & \\
\hline Convenient places for assistive device rental for TwMI & 0.603 & & \\
\hline Convenient view of event programs for TwMI & 0.588 & & \\
\hline Convenient entrance for TwMI & 0.553 & & \\
\hline Convenient use of restaurant with TwMI & 0.527 & & \\
\hline Service provider quality for TwMI & & 1.138 & 10.347 \\
\hline Staff are located proper location for TwMI & 0.906 & & \\
\hline Staff are kind to TwMI & 0.810 & & \\
\hline Staff possesses proper information for TwMI & 0.766 & & \\
\hline Staff are willing to help for TwMI & 0.689 & & \\
\hline
\end{tabular}

Note. Total explained variance $=58.8 \%$, KMO measure of sampling adequacy $=0.863$, Bartlett's test of sphericity $(p<0.001)$, Cronbach alpha coefficient of 11 event service quality items $=0.890$. 
Table 4

The Result of Confirmatory Factor Analysis

\begin{tabular}{|c|c|c|c|c|}
\hline & $\begin{array}{l}\text { Standard Factor } \\
\text { Loading }\end{array}$ & $S E$ & $t$ Value & CR \\
\hline Service environment quality & & & & 0.821 \\
\hline Convenient move in the event area for TwMI & 0.681 & 0.130 & 7.420 & \\
\hline Well-equipped assistive device (e.g., wheelchair) for TwMI & 0.623 & 0.124 & 6.991 & \\
\hline Convenient use of restroom for TwMI & 0.528 & 0.129 & 6.217 & \\
\hline Convenient places for assistive device rental for TwMI & 0.663 & 0.140 & 7.310 & \\
\hline Convenient view of event programs for TwMI & 0.599 & 0.142 & 6.806 & \\
\hline Convenient entrance for TwMI & 0.721 & 0.156 & 7.704 & \\
\hline Convenient use of restaurant with TwMI & 0.576 & NA & NA & \\
\hline Service provider quality & & & & 0.896 \\
\hline Staff are located proper location for TwMI & 0.819 & 0.087 & 12.953 & \\
\hline Staff are kind to TwMI & 0.854 & 0.079 & 13.591 & \\
\hline Staff possesses proper information for TwMI & 0.677 & 0.109 & 9.226 & \\
\hline Staff are willing to help for TwMI & 0.811 & NA & NA & \\
\hline Caregivers' event satisfaction with TwMI & & & & 0.853 \\
\hline Overall satisfied event with TwMI & 0.869 & 0.062 & 15.200 & \\
\hline Satisfied event with TwMI when compared with my expectation & 0.895 & 0.065 & 15.792 & \\
\hline Satisfied event with TwMI when considering my invested time and effort & 0.827 & NA & NA & \\
\hline Caregivers' behavior intention & & & & 0.896 \\
\hline Willing visit other similar events with TwMI & 0.908 & 0.073 & 16.230 & \\
\hline Willing to say positive things about the event to other caregivers or TwMI & 0.935 & 0.073 & 16.835 & \\
\hline Willing to recommend the event to other caregivers or TwMI & 0.812 & NA & NA & \\
\hline
\end{tabular}

Note. $\chi^{2} / d f=245.137 / 109=2.249, \mathrm{CFI}=0.940, \mathrm{TLI}=0.925, \mathrm{IFI}=0.941, \mathrm{RMSEA}=0.077$.

of the measurement scales (Hair, Black, Babin, Anderson, \& Tatham, 2005).

From the results of CFA, Table 4 presents the composite reliability of the multi-item scales using Cronbach's alpha ranging from 0.821 to 0.896 , which showed all of the alpha coefficients were above the cut-off point of 0.7 (Nunnally, 1978). The results of CFA showed that the overall fit indices display an acceptable level of fit: $\chi^{2}(109)=245.137, p<0.001$, comparative fit index $(\mathrm{CFI})=0.940$, incremental fit index $(\mathrm{IFI})=0.941$, Tucker Lewis Index $(\mathrm{TLI})=0.925$, root mean square error of approximation (RMSEA) $=0.077$ (0.064-0.089). In addition, all of the indicators of the $t$ value associated with each of the completely standardized loading exceeded the critical value (2.58) at $p<0.001$ significance level. Therefore, overall measurement model showed a theoretically meaningful and statistically acceptable model, as indicated by Table 4 .

An empirical structural equation model was tested to see if the hypothesized model was reliable with the collected data after confirmed confidence from the proposed measurement model of this study. For this, SEM was employed to examine the relationship among event service quality for TwMI, caregivers' event satisfaction with TwMI, and caregivers' behavior intention. Event service quality for TwMI includes two dimensions (service environment quality, service provider quality) as exogenous constructs while two endogenous constructs were caregivers' event satisfaction with TwMI and caregivers' behavior intention. The results of SEM indicated the overall fit index displays an acceptable level of fit: $\chi^{2}(109)=245.137$, $p<0.001$, CFI $=0.940$, IFI $=0.941$, TLI $=0.925$, RMSEA $=0.077(0.064-0.089)$. In addition, the results of the squared multiple correlations showed $34 \%$ of the variance in the event satisfaction with TwMI, and $69 \%$ of the variance in the behavior intention.

With the maximum likelihood estimation method, the completely standardized coefficients were evaluated. As shown in Figure 2, between two dimensions of event service quality for TwMI, only service environment quality was statistically significant $(\beta=0.57, S E=0.175, p<0.001)$ on event satisfaction with TwMI (supporting H1a), while there is no direct effect between service environment quality and behavior intention. Therefore, 


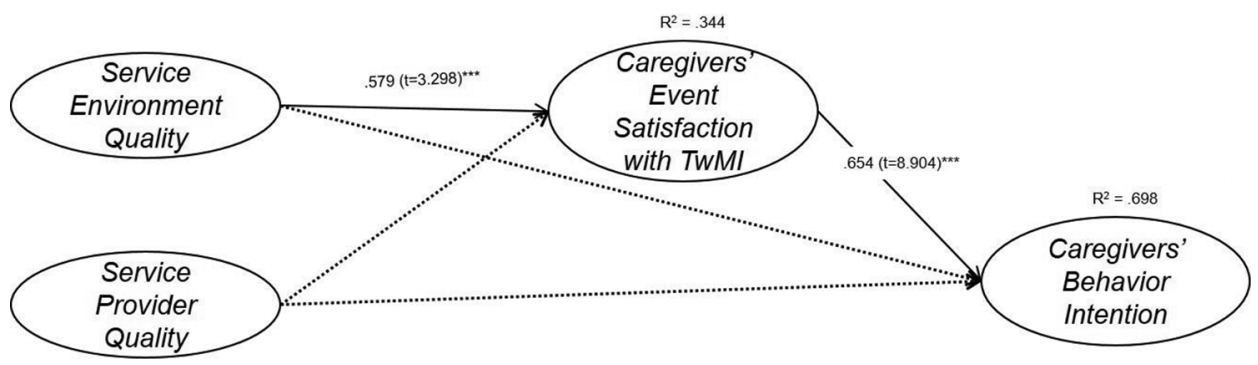

Figure 2. Conceptual research model with structural model testing.

$\mathrm{H} 1 \mathrm{~b}, \mathrm{H} 2 \mathrm{a}$, and $\mathrm{H} 2 \mathrm{~b}$ are rejected. In the path coefficient from the event satisfaction with TwMI to behavior intention, it was found that the completely standardized coefficient was statistically significant $(\beta=0.65, S E=0.073, p<0.001)$ and the magnitude of coefficients scores indicated largest influence on behavior intention. Therefore, H3 is supported. This result indicates that event satisfaction with TwMI had a significant impact on behavior intention such as revisit other similar events with TwMI and recommend visiting the event to other caregivers or TwMI.

\section{Conclusion}

\section{Theoretical Contributions}

The purpose of this study was to develop a theoretical model of event service quality for TwMI from the caregiver's point of view. This study empirically examined the relationships among event service quality for TwMI, a caregiver's event satisfaction with TwMI, and a caregiver's behavior intention in the case of South Korea. Unlike normal event service quality for abled people from previous research, this study is the first to conduct event service quality for TwMI in terms of the perspective of caregivers. In addition, because this study aimed to examine event service quality for TwMI through the caregiver's perspective, finding the decision maker for visiting the event was critically important to vindicate this study as meaningful. As initially emphasized about the importance of the caregiver's role when traveling with TwMI, caregivers, including public organizations (86\%), mostly decided to visit the event. Because the result of the decisionmaking process to visit the event was mostly led by caregivers, it implies that knowing the perspective of caregivers about event service quality for TwMI is significant to expedite more event participation with TwMI.

Based on the empirical tests of the hypothesized SEM model in this study, from the exogenous variables, service environment quality for TwMI was only statistically significant on caregivers' event satisfaction with TwMI. From endogenous variables, caregivers' event satisfaction with TwMI showed statistically significant on caregivers' behavior intention. Subsequently, caregivers' event satisfaction with TwMI played a full mediating role in the relationship between service environment quality for TwMI and caregivers' behavior intention. Service environment quality for TwMI plays an important role in caregivers' event satisfaction with TwMI, which in turn influences caregivers' behavior intention. Therefore, it is important to check detailed elements with service environment quality for TwMI.

From the initial interviews with caregivers who accompanied TwMI at the event, as the majority of past research pointed out the importance of accessibility in terms of people with disabilities' perspective, caregivers' perspective also showed accessible oriented and customized service for TwMI. In detail, caregivers who accompanied TwMI were mostly concerned with convenient use of facilities for TwMI (i.e., restroom, restaurant), convenient movement in the event for TwMI, and convenient assistive device use for TwMI (i.e., rental, well equipped) in the event area. Among service environment quality for TwMI, convenient use of restroom was most frequently mentioned by caregivers and it was marked with the highest mean score (6.04 out of 7 Likert scale) among service 
environment for TwMI factors. Although convenient use of restroom and restaurant are important for service quality for abled people (J. S. Lee et al., 2011), caregivers who accompanied with TwMI especially prioritized restroom as important for accessible and convenient use. This result can be supported from other therapy research related to people with spinal cord injury because bladder and bowel are one of the main issues that interrupt both daily and social activities for TwMI (BloemenVrencken, Post, Hendriks, De Reus, \& De Witte, 2005). Therefore, event managers especially need to give extra attention to convenient use of restrooms for TwMI to maintain high quality of service environment.

From the interview with caregivers, although convenient use of restaurant is also important for caregivers who visited the event with TwMI, caregivers marked lowest score (4.31 out of 7 Likert scale) because most restaurants in the event area were outsourced and focused on profit (e.g., as TwMI occupy more space than normal customer and take more time to take care for them) rather than giving consideration to TwMI. However, as caregivers consider convenient use of restaurant as meaningful time with care recipients, securing enough space and providing proper service are required for high quality of service environment, which in turn affects event satisfaction and positive behavior intention.

Convenient location for assistive device rental and well-equipped assistive devices at the event were also important elements for high quality of event service environment for TwMI from the caregivers' perspective. These two items were especially essential at the event area because more than $90 \%$ of caregivers are family members and they had limited space for assistive device (i.e., wheelchair, electronic wheelchair) in the car when they travel from home to the event. Considering this condition, well-equipped and proper location for renting various assistive devices (e.g., wheelchair, electronic wheelchair) at the event might provide caregivers with less of a burden when visiting the event. The findings of this study related to rental device are consistent with research by Shi et al. (2012) because TwMI importantly comment, "the availability of mobility-aids such as scooter rentals" at the travel destinations influence travel decisions (p. 230). Therefore, electronic wheelchairs might be especially good for easy movement in the event area because many older adults were TwMI at the event.

Caregivers also weighted convenient accessibility with entrance, event programs, and event area. Because the expo provided wide space for wheelchair movement in the event area and secured separate lines for convenient entrance and event programs, caregivers were highly satisfied with this consideration by the event. As caregivers also want to enjoy the time in the event with TwMI, better accessible environment is critical when caregivers visit events with TwMI. Overall, these results could shed new light on the importance of event service environment for TwMI including convenient use of facilities for both caregivers and care recipients.

On the other hand, there is no statistical significance on service provider quality for TwMI on either caregivers' event satisfaction with TwMI or caregivers' behavior intentions in terms of caregivers' point of view. However, the result of descriptive analysis of this study showed that service provider for TwMI factors were quite favorable with mean score range by 4 items indicated from 4.8 to 5.2 score out of 7 Likert scale. This result shows that the role of caregivers is likely to pay more attention to mitigate barriers and seek solutions for TwMI. The one possible interpretation with this result, because caregivers are indirectly related with service providers compared to TwMI, service provider quality for TwMI might less affect caregivers' event satisfaction and caregivers' behavior intention. In addition, service provider quality for TwMI might be more difficult to measure with objectivity by caregivers compared to service environment quality for TwMI.

Therefore, although event service provider quality for TwMI had no statistically significant influence on caregivers' event satisfaction and caregivers' behavior intention in terms of caregivers' point of view, still the need for service provider quality for TwMI is essential and important as many TwMI consider service provider quality as valuable as service environment quality. Research by Shi et al. (2012) supported the importance of service providers' attitude toward people with disability, as travelers with acquired mobility impairments mentioned that a warm attitude of service providers toward 
people with disability could be more important than physically inaccessible environments because people with disability would neither visit a destination nor recommend others where service providers treat them with negative attitudes. In conclusion, although service provider quality for TwMI is not statistically significant for caregivers' event satisfaction with TwMI and caregivers' behavior intention in this study, the significant importance of service provider quality for TwMI is indisputable.

\section{Practical Implications}

Practical recommendation from this study is that when planning and organizing events, because service environment quality for TwMI is the most important factor for caregivers' event satisfaction with TwMI and behavioral intention, it is necessary to provide and improve a more accessible environment and convenient assistive device use in the event. Under this circumstance, both caregivers and care recipients enjoy the event and visit another similar events. Therefore, results of this study should help event organizers to develop and improve better service quality for people with disabilities because caregivers with people with disabilities are the largest and fastest growing niche markets in the travel industry.

\section{Limitations and Future Research}

Although this study is highly important for both theoretically and practically understanding event service quality for TwMI in terms of caregivers' point of view, several limitations still exist, which in turn provide implications and suggestions for future research. First, because core service recipients are TwMI, their voice also should be inserted for balanced knowledge of service quality for TwMI although caregivers' perspective is important to find out service quality for TwMI. Second, participants in this study are limited to caregivers who accompanied TwMI. Because many other people with disabilities (e.g., people with hearing impairments, people with sight impairments) also have difficulty in travel, a study with caregivers who accompanied other people with disabilities might be needed for further research. Third, this study is only designed for event service quality for TwMI, although many other travel sectors (i.e., hotel, travel destination, airport) also play an important role in decision making by caregivers. Therefore, it is recommended to conduct service quality study with various travel places by both caregivers and care recipients. Fourth, this study was only conducted in a mega-event in South Korea. Therefore, it is difficult to apply to other events and countries, especially Western countries. Because Korea is more oriented toward family relationships and mostly rely on caregivers, even in daily life, it is possible self-oriented and well-designed accessibility in a Western country might have different outcomes. Hence, conducting the research in Western countries is also recommended.

\section{References}

Avis, A. H., Card, J. A., \& Cole, S. T. (2005). Accessibility and attitudinal barriers encountered by travelers with physical disabilities. Tourism Review International, 8(3), 239-248.

Arbuckle, J. L. A. (2006). AMOS 7.0 user's guide. Spring House, PA: Amos Development Corporation.

Baker, D. A., \& Crompton, J. L. (2000). Quality, satisfaction and behavioral intentions. Annals of Tourism Research, 27(3), 785-804.

Bedini, A. B. (2002). Family caregivers and leisure: An oxymoron? Parks and Recreation, 37(1), 25-31.

Bi, Y., Card, J. A., \& Cole, S. T. (2007). Accessibility and attitudinal barriers encountered by Chinese travellers with physical disabilities. International Journal of Tourism Research, 9(3), 205-216.

Bitner, M. J. (1992). Servicescapes: The impact of physical surroundings on customers and employees. The Journal of Marketing, 56(2), 57-71.

Bloemen-Vrencken, J. H., Post, M. W., Hendriks, J. M., De Reus, E. C., \& De Witte, L. P. (2005). Health problems of persons with spinal cord injury living in the Netherlands. Disability \& Rehabilitation, 27(22), 1381-1389.

Bombom, L. S., \& Abdullahi, I. (2016). Travel patterns and challenges of physically disabled persons in Nigeria. GeoJournal, 81(4), 519-533.

Brady, M. K., \& Cronin Jr, J. J. (2001). Some new thoughts on conceptualizing perceived service quality: A hierarchical approach. Journal of Marketing, 65(3), 34-49.

Brady, M. K., \& Robertson, C. J. (2001). Searching for a consensus on the antecedent role of service quality and satisfaction: An exploratory cross-national study. Journal of Business research, 51(1), 53-60.

Brault, M. W. (2012). Americans with disabilities: 2010: Household economic studies. Suitland, MD: US Department of Commerce, Economics and Statistics Administration, US Census Bureau. 
Brown, T. J., Kaplan, R., \& Quaderer, G. (1999). Beyond accessibility: Preference for natural areas. Therapeutic Recreation Journal, 33(3), 209-221.

Burnett, J. J., \& Baker, H. B. (2001). Assessing the travelrelated behaviors of the mobility-disabled consumer. Journal of Travel Research, 40(1), 4-11.

Cole, S. T., \& Illum, S. F. (2006). Examining the mediating role of festival visitors' satisfaction in the relationship between service quality and behavioral intentions. Journal of Vacation Marketing, 12(2), 160-173.

Cole, S. T., \& Scott, D. (2004). Examining the mediating role of experience quality in a model of tourist experiences. Journal of Travel \& Tourism Marketing, 16(1), 79-90.

Crompton, J. L., \& Love, L. L. (1995). The predictive validity of alternative approaches to valuating quality of a festival. Journal of Travel Research, 34(1), 11-24.

Cronin, J. J., Brady, M. K., \& Hult, G. T. M. (2000). Assessing the effects of quality, value, and customer satisfaction on consumer behavioral intentions in service environments. Journal of Retailing, 76(2), 193-218.

Daniels, M. J., Rodgers, E. B. D., \& Wiggins, B. P. (2005). "Travel tales": An interpretive analysis of constraints and negotiations to pleasure travel as experienced by persons with physical disabilities. Tourism Management, 26(6), 919-930.

Darcy, S., \& Daruwalla, P. S. (1999). The trouble with travel: People with disabilities and tourism. Social Alternatives, 18(1), 41-46.

Doshi, J. K., Furlan, A. D., Lopes, L. C., DeLisa, J., \& Battistella, L. R. (2014). Conferences and convention centres' accessibility to people with disabilities. Journal of Rehabilitation Medicine, 46(7), 616-619.

Getz, D., O’Neill, M., \& Carlsen, J. (2001). Service quality evaluation at events through service mapping. Journal of Travel Research, 39(4), 380-390.

Getz, D., \& Page, S. J. (2016). Progress and prospects for event tourism research. Tourism Management, 52, $593-631$.

Gladwell, N. J., \& Bedini, L. A. (2004). In search of lost leisure: The impact of caregiving on leisure travel. Tourism Management, 25, 685-698.

Gnoth, J. (1997). Tourism motivation and expectation formation. Annals of Tourism Research 24(2), 283-304.

Hair, F. Jr., Black, W. C., Babin, B. J., Anderson, R. E., \& Tatham, R. L. (2005). Multivariate data analysis (6th ed.). Upper Saddle River, NJ: Prentice Hall.

Hall, S., Oriade, A., \& Robinson, P. (2016). Assessing festival attendees' behavioral intentions through perceived service quality and visitor satisfaction. Event Management, 20(1), 27-40.

Hansemark, O. C., \& Albinson, M. (2004). Customer satisfaction and retention: The experiences of individual employees. Managing Service Quality, 14(1), 40-57.

Huh, C., \& Singh, A. (2007). Families travelling with a disabled member: Analysing the potential of an emerging niche market segment. Tourism and Hospitality Research, 7(3/4). 212-229.
Israeli, A. A. (2002). A preliminary investigation of the importance of site accessibility factors for disabled tourists. Journal of Travel Research, 41(1), 101-104.

Jeong, A., An, J. Y. M., Park, J. H., \& Park, K. (2016). What cancer means to the patients and their primary caregivers in the family-accounted Korean context: A dyadic interpretation. Psycho Oncology, 1-7.

Kahn, J. (2000). Creating an online community-And a market-For the disabled. Fortune, 7, 188.

Kelly, S. W., \& Turley, L. W. (2001). Consumer perceptions of service quality attributes at sporting events. Journal of Business Research, 54(2), 161-166.

Kline, R. B. (2005), Principles and practice of structural equation modeling (2nd ed.). New York, NY: Guilford.

Korea Employment Agency for the Disabled. (2015). 2014 employment status of people with disabilities. Retrieved from https://www.kead.or.kr

Lee, B. K., Agarwal, S., \& Kim, H. J. (2012). Influences of travel constraints on the people with disabilities' intention to travel: An application of Seligman's helplessness theory. Tourism Management, 33(3), 569-579.

Lee, C. K., Yoon, Y. S., \& Lee, S. K. (2007). Investigating the relationships among perceived value, satisfaction, and recommendations: The case of the Korean DMZ. Tourism Management, 28(1), 204-214.

Lee, J. S., Lee, C. K., \& Choi, Y. J. (2011). Examining the role of emotional and functional values in festival evaluation. Journal of Travel Research, 50(6), 685-696.

Lee, J. S., Lee, C. K., \& Yoon, Y. (2009). Investigating differences in antecedents to value between first-time and repeat festival-goers. Journal of Travel \& Tourism Marketing, 26(7), 688-702.

Lee, Y. K., Lee, C. K., Lee, S. K., \& Babin, B. J. (2008). Festivalscapes and patrons' emotions, satisfaction, and loyalty. Journal of Business Research, 61(1), 56-64.

Lyu, S. O. (2017). Which accessible travel products are people with disabilities willing to pay more? A choice experiment. Tourism Management, 59, 404-412.

Lyu, S. O., Oh, C. O., \& Lee, H. (2013). The influence of extraversion on leisure constraints negotiation process: A case of Korean people with disabilities. Journal of Leisure Research, 45(2), 233-252.

Mason, M. C., \& Nassivera, F. (2013). A conceptualization of the relationships between quality, satisfaction, behavioral intention, and awareness of a festival. Journal of Hospitality Marketing \& Management, 22(2), 162-182.

McKercher, B., Packer, T., Yau, M. K., \& Lam, P. (2003). Travel agents as facilitators or inhibitors of travel: Perceptions of people with disabilities. Tourism Management, 24(4), 465-474.

Murray, K. B., \& Schlacter, J. L. (1990). The impact of services versus goods on consumers' assessment of perceived risk and variability. Journal of the Academy of Marketing Science, 18(1), 51-65.

Nunnally, J. C. (1978). Psychometric theory. New York, NY: McGraw-Hill.

Nunnally, J. C., \& Bernstein, I. (1994). Psychometric theory (3rd ed.). New York, NY: McGraw-Hill. 
Parasuraman, A., Zeithaml, V. A., \& Berry, L. L. (1985). A conceptual model of service quality and its implications for future research. Journal of Marketing, 49, 41-50.

Ray, N. M., \& Ryder, M. E. (2003). "Ebilities" tourism: An exploratory discussion of the travel needs and motivations of the mobility-disabled. Tourism Management, 24, $57-72$.

Sato, M., Yoshida, M., Wakayoshi, K., \& Shonk, D. J. (2016). Event satisfaction, leisure involvement and life satisfaction at a walking event: The mediating role of life domain satisfaction. Leisure Studies, 36(5), 605-617.

Shaw, G., \& Coles, T. (2004). Disability, holiday making and the tourism industry in the UK: A preliminary survey. Tourism Management, 25(3), 397-403.

Shi, L., Cole, S., \& Chancellor, C. H. (2012). Understanding leisure travel motivations of travelers with acquired mobility impairments. Tourism Management, 33(1), 228-231.

Song, H. J., Ahn, Y. J., \& Lee, C. K. (2015). Examining relationships among Expo experiences, service quality, satisfaction, and the effect of the Expo: The case of the Expo 2012 Yeosu Korea. Asia Pacific Journal of Tourism Research, 20(11), 1266-1285.

Stum, D. L., \& Thiry, A. (1991). Building customer loyalty. Training and Development Journal, 45(4), 34-36.
Takeda, K., \& Card, J. A. (2002). US tour operators and travel agencies: Barriers encountered when providing package tours to people who have difficulty walking. Journal of Travel \& Tourism Marketing, 12(1), 47-61.

Theodorakis, N. D., Kaplanidou, K., \& Karabaxoglou, I. (2015). Effect of event service quality and satisfaction on happiness among runners of a recurring sport event. Leisure Sciences, 37(1), 87-107.

Turco, D. M., Stumbo, N., \& Garncarz, J. (1998). Tourism constraints for people with disabilities. Parks \& Recreation, 33(9), 78-84.

Wiles, J. (2003). Daily geographies of caregivers: Mobility, routine, scale. Social Science \& Medicine, 57(7), 1307-1325.

Yates, M. E., Tennstedt, S., \& Chang, B. H. (1999). Contributors to and mediators of psychological well-being for informal caregivers. Journal of Gerontology, 54(1), $12-22$.

Yau, M. K. S., McKercher, B., \& Packer, T. L. (2004). Traveling with a disability: More than an access issue. Annals of Tourism Research, 31(4), 946-960.

Zeithaml, V. A., Berry, L. L., \& Parasuraman, A. (1996). The behavioral consequences of service quality. Journal of Marketing, 60(4), 31-46. 
Copyright of Event Management is the property of Cognizant, LLC and its content may not be copied or emailed to multiple sites or posted to a listserv without the copyright holder's express written permission. However, users may print, download, or email articles for individual use. 